\title{
Clientelismo y corrupción: ¿afinidades electivas? Una aproximación mediante estudios de caso
}

\author{
Clientelism and corruption: Elective affinities? \\ An approach through case studies
}

JOSÉ PANTÍN

Universidad de Santiago de Compostela

RAMÓN MÁIZ

Universidad de Santiago de Compostela

\section{Cómo citar/Citation}

Pantín, J. y Máiz, R. (2019). Clientelismo y corrupción: ¿afinidades electivas? Una aproximación mediante estudios de caso. Revista Española de Ciencia Política, 51, 13-37. Doi: Disponible en: https://doi.org/10.21308/recp.51.01

\section{Resumen}

Este artículo forma parte de una serie de investigaciones sobre el fenómeno del clientelismo político en Galicia (España). El objetivo principal es comprobar la relación teórica y empírica entre el fenómeno del clientelismo y su financiación por métodos corruptos. El artículo utiliza una definición teórica de clientelismo y corrupción como fenómenos diferenciados, pero que pueden llegar a ser interdependientes y superponerse en un plano empírico, dando origen a fenómenos híbridos. El texto propone un marco analítico para explorar el nexo entre ambos conceptos, especialmente cuando la corrupción se convierte en un instrumento de financiación de las redes clientelares. El artículo presenta los resultados de una investigación original, basada en tres minuciosos estudios de caso de relaciones clientelares donde se ha producido corrupción política para financiar la maquinaria partidista y distribuir favores.

Palabras clave: corrupción, clientelismo, patronazgo, compra de voto, Galicia, estudio de caso, redes, máquina política, partidos políticos, favores.

\begin{abstract}
This article is part of a series of investigations on the phenomenon of political clientelism in Galicia (Spain). The main objective is to verify the theoretical and empirical relationship between the phenomenon of clientelism and its funding through corrupt methods. The article uses a theoretical definition of clientelism and corruption as differentiated phenomena that
\end{abstract}


can, nevertheless, become interdependent and overlapping at an empirical plane. This, in turn, gives rise to hybrid phenomena. The text proposes an analytical framework to explore the linkage between both concepts, especially when corruption becomes an instrument for financing patron-client networks. The paper presents the results of an original research based on three thorough case studies of clientelistic relationship where political corruption has taken place to finance the party machine and distribute favours.

Keywords: corruption, clientelism, networks, patronage, vote buying, Galicia, case study, political machine, political parties, favors.

Tú me cuidas, yo te cuido

Broker, Ría de Arousa

\section{INTRODUCCIÓN}

"Llamamos afines a aquellas naturalezas que al encontrarse se aferran con rapidez las unas a las otras y se determinan mutuamente», decía el personaje de la célebre novela de Goethe de 1809. Para Max Weber, las afinidades electivas designan el proceso por el cual «dos formas culturales —intelectuales, políticas, económicas- entran, a partir de ciertas analogías, en una relación de atracción e influencia recíproca, convergencia activa y reforzamiento mutuo» (citado en Löwy, 2004: 100). Esta metáfora literaria puede iluminar la hibridación entre clientelismo y corrupción que se produce en determinados contextos y que constituirá el eje de este artículo. Con mucha frecuencia se utiliza el concepto de clientelismo como fenómeno relacionado o incluso equivalente al de corrupción. Sin embargo, la política de focalizar gasto público en los votantes no constituye un subtipo de corrupción, sino un modelo de gestión de los recursos con criterios de eficiencia electoral, un régimen de favoritismo donde recibir un beneficio directo y particularizado requiere la reciprocidad personalizada mediante apoyo político. La relación clientelar se basa en la lógica del intercambio directo de favores por apoyo político, un contrato informal quid pro quo eficiente para movilizar recursos hacia los sujetos leales, lo cual produce una tupida trama de intereses, con numerosos beneficiarios y escasos incentivos para romper la colaboración.

La distribución de favores clientelares podrían a dividirse en dos tipos: a) los circunscritos al marco teórico del clientelismo, y b) los que invaden algunas características propias de la corrupción. El primero es un mecanismo de rendición de cuentas ante el electorado basado en las políticas dirigidas, particularistas, no universales, sin ocultar a la sociedad el favor otorgado; el segundo se produce cuando los políticos utilizan el cargo para un beneficio personal o del partido, de forma ilegal y mediante un intercambio oculto a la sociedad. En este segundo caso, a diferencia del clientelismo, los únicos beneficiados son pequeños círculos de corruptos. Así, el beneficio que recibe 
el político clientelar es muy distinto del que recibe un político que cuida a su electorado y segmenta sus políticas, por lo cual no parece conveniente calificar como corrupto toda acción de carácter político que de alguna manera beneficie al agente.

Se ha podido detectar la copresencia y refuerzo mutuo del fenómeno clientelar y el corrupto. El propósito de este trabajo es ofrecer una respuesta a la naturaleza y alcance de su imbricación, y en particular a la cuestión: ¿por qué a menudo el clientelismo y la corrupción se entrelazan en un plano empírico si en el debate teórico han sido fijadas, con solidez, sus diferencias?

El trabajo de campo original en que se basan estas páginas consiste en tres estudios de caso realizados mediante un laborioso proceso de varios años de observación. Los casos 1 y 2 corresponden a alcaldes-patrones que dominaron la vida política en sendos municipios de mediano tamaño durante muchos años; el caso 3 analiza el comportamiento del presidente de una diputación provincial que utilizó la institución, también durante largo período de tiempo, para comprar estratégicamente los apoyos necesarios en los municipios de la provincia. Para garantizar el anonimato, los casos y protagonistas son tratados con seudónimos.

Una vez planteada esta breve introducción, en el siguiente apartado se explorará la literatura sobre el clientelismo político como un fenómeno difuso y con muchas interpretaciones; a continuación se discutirán sus similitudes y diferencias respecto al concepto de corrupción política; en el cuarto apartado se presenta el contexto, planteamiento y metodología; el quinto apartado presenta los estudios de caso de tres patrones locales, cuya historia está protagonizada por el clientelismo y la corrupción. El artículo finaliza con la discusión de los resultados y la síntesis de los hallazgos más relevantes, seguido de unas breves conclusiones.

\section{¿QUÉ ES EL CLIENTELISMO?}

El clientelismo político consiste en una relación de intercambio directo - esto es, no mediado por programas e ideologías - de votos por favores entre dos personas de estatus desigual (Scott, 1972; Castañeda, 2018). Patrones y clientes establecen vínculos de amistad instrumental, relaciones interpersonales diádicas (cara a cara) que se producen bajo reglas de lealtad y confianza. La suma de díadas forma redes clientelares de estructura piramidal (Flap, 1990; Kitschelt y Wilkinson, 2007), con patrones conectados con muchos clientes que estructuran un sistema asimétrico de favores dentro de las instituciones, donde el acceso a los recursos públicos (Eisenstadt y Roniger, 1984; Geddes, 1994; Della Porta y Mény, 1995) permite distribuirlos de manera selectiva y personalizada (Castañeda, 2018) y satisfacer pequeñas demandas no atendidas por la política y burocracia oficiales.

El sistema de favores clientelar satisface de modo informal muchas de las funciones del mercado o la burocracia, desarrollando un modo de ejercicio del poder por parte de un partido político con líderes que utilizan las instituciones y los recursos públicos para hacer favores y lograr que terceros contraigan deudas con ellos (Graziano, 1984). 
La estructura política vertical patrones-clientes impide la agregación horizontal de demandas políticas y la organización de los intereses colectivos, y fomenta la competencia entre clientes para acercarse al patrón (Roniger y Günes-Ayata, 1994, 2005).

El retorno de los favores se garantiza mediante la vigilancia de los votantes por parte de brokers, agentes electorales que intermedian entre patrones y clientes para monitorizar y distribuir los favores (Kitschelt y Wilkinson, 2007), especialmente en circunscripciones/comunidades pequeñas controladas por los partidos de masas (Medina y Stokes, 2007), que actúan en ellas como partidos clientelares para dirigir con precisión selectiva los beneficios/sanciones de la política clientelar e, incluso, excluir de las políticas a los ciudadanos no colaboradores en los intercambios.

El clientelismo moderno depende del soporte de una organización informal parcialmente articulada con la estructura formal de un partido. La máquina política aglutina poder al contar con miembros poderosos en cargos institucionales y una estructura reticular de implantación territorial que le permite llegar a los votantes con notable eficacia (Merton, 1964; Graziano, 1984; Coleman, 1990; Roniger y Günes-Ayata, 1994; Castañeda 2018). Este sistema se convierte en un tipo de vínculo para la rendición de cuentas opuesto a la accountability democrática que se produce dentro de los partidos programáticos, los cuales ofrecen una ideología y un proyecto político con políticas públicas universales (no particularistas) que no discriminan entre los votantes en función del sentido de su voto.

El refuerzo del voto programático se produce bajo distintas coyunturas: pérdida de reputación del patrón, transformaciones socioculturales, crecimiento económico o la presencia de alternativas programáticas de prestigio con capacidad movilizadora (Eisenstadt y Lemarchand, 1981; Kitschelt, 2000; Stokes et al., 2013). En cambio, cuando los beneficios de las políticas públicas no llegan debidamente a los ciudadanos y la movilidad social no se basa en la justicia y el mérito, los clientes se centrarán en la procura de «amigos políticos» instrumentales (lopsided friendship), en conseguir el favor de los patrones para competir con ventaja contra otros ciudadanos (Gambetta, 1988; Chubb, 1982).

La literatura más actualizada diferencia entre dos modalidades de clientelismo: a) los autores identifican la estrategia del patronage cuando las máquinas políticas orientan su acción hacia los miembros del partido para controlar la organización, mientras que b) cuando las máquinas hacen favores para atraer el voto electoral de miembros de fuera del partido, la práctica se convierte en «vote buying» (Stokes et al., 2013). Sin embargo, lo común en la literatura ha sido utilizar indistintamente el concepto de clientelismo y patronazgo.

\section{DIFERENCIAS Y SIMILITUDES ENTRE CLIENTELISMO Y CORRUPCIÓN}

Los especialistas entienden por corrupción, de manera general, un uso indebido —o abuso- de una posición oficial (del cargo y los recursos públicos) para fines, 
ventajas y beneficios privados (Huntington, 1968; Johnston, 1986; Heidenheimer $e t$ al., 1989; Theobald, 1990; Della Porta, 1992; Caciagli, 1996; Heywood, 1996; Villoria, 2006). El análisis de la corrupción, sea cual sea su enfoque, debe diferenciar entre el sujeto que la ejecuta (político, administrativo, empresarial), el fin perseguido (enriquecimiento o poder político) y el bien esencial dañado (eficiencia empresarial, confianza, legitimidad política, principio de imparcialidad administrativa) (ibid., 2006: 96).

Manuel Villoria (1996) sintetiza los distintos enfoques de la corrupción por disciplinas. Para la ciencia política consiste en la toma de decisiones parciales o para un sector social concreto a cambio de beneficios directos o indirectos de manera oculta y fuera de los cauces normales de negociación. En los casos analizados el clientelismo era público y notorio; en cambio, los hechos ilegales y corruptos permanecían ocultos en buena medida. Desde la sociología, la corrupción está vinculada a lo que se considera o no corrupto en función del contexto histórico, una percepción particular de cada sociedad. La ética nos habla de actos contrarios a las normas no escritas. Las percepciones sociales (recogidas en el trabajo de campo) sobre el modelo de gestión clientelar, se relacionaban con la política de proximidad y con cuidar al electorado, no con la corrupción. La corrupción desde la perspectiva del derecho consiste en la violación de las obligaciones del cargo en aras del beneficio propio, tipificada en hechos corruptos: La corrupción comienza cuando la norma legal se quebranta.

La literatura diferencia la corrupción de otros fenómenos. A continuación trataremos de especificar sus mecanismos fundamentales en comparación con el clientelismo. La corrupción política se define como el «intercambio de decisiones públicas por dinero, y el clientelismo se concretiza en un intercambio de favores por votos» (Della Porta y Mény, 1995: 51). En la corrupción «un titular de derechos y deberes públicos los aprovecha para ganar una posición de estatus, para una ventaja personal o para una ventaja financiera privada para él mismo, para su familia, para grupos profesionales, para el partido" (Caciagli, 1996: 54), pero lo que destaca de los abusos corruptos sobre otras discrecionalidades es el dinero y los recursos que valgan dinero. A diferencia del clientelismo, en la corrupción los actores están en el mismo nivel, el vínculo es siempre horizontal y voluntario en una relación entre iguales; en cambio, el clientelismo se caracteriza por las relaciones de dependencia, verticalidad y sumisión entre agentes (ibid.).

La corrupción destinada al lucro personal requiere de «transacciones entre los sectores privado y público de tal manera que los bienes colectivos se convierten ilegítimamente en privados» (Heidenheimer et al., 1989: 6). Por ello, las prácticas corruptas de los partidos no constituyen clientelismo porque «ni toda corrupción es debida a la máquina [de los partidos] ni toda política de la máquina es corrupta» (Scott, 1974).

En una elaboración más pormenorizada de la distinción clientelismo-corrupción, si bien ambos comparten su concepción particularista, la motivación de la corrupción política es el enriquecimiento personal ilegal (Theobald, 1990), mientras que la del clientelismo es distribuir los recursos públicos con eficiencia electoral (Stokes et al., 2013). La mercancía de la corrupción es el dinero, y la del clientelismo son los votos 
y favores con unos componentes simbólicos y de administración discrecional que en ocasiones no son considerados corruptos ni ilegales. Sin embargo, las prácticas clientelares devienen corrupción cuando en el proceso de provisión de recursos incurren en irregularidades y prevaricación y, por supuesto, si se malversa para repartir bienes a la red y financiar el gasto de las organizaciones clientelares (Della Porta y Mény, 1995).

TABLA 1.

ELEMENTOS COMUNES Y PARTICULARES DEL CLIENTELISMO Y LA CORRUPCIÓN

\begin{tabular}{cc}
\hline \multicolumn{2}{c}{ Diferencias } \\
\hline Corrupción & Clientelismo \\
\hline Privado & Político \\
Dinero & Apoyo \\
Ilegalidad & Ilegalidad \\
Oculto & Manifiesto \\
Compinche & Votante \\
Socio & Cliente \\
Horizontal & Vertical \\
Igualdad & Desigualdad \\
Arbitrario & Discrecional \\
Interdependencia & Dependencia \\
\hline
\end{tabular}

\begin{tabular}{cc}
\hline \multicolumn{2}{c}{ Similitudes } \\
\hline Corrupción & Clientelar \\
\hline Individuo & Individuo \\
Informal & Informal \\
Focalizado & Focalizado \\
Pragmatismo & Pragmatismo \\
Particular & Particular \\
Inmoral & Inmoral \\
\hline
\end{tabular}

Fuente: elaboración propia.

Con el objetivo de alcanzar una definición operativa y comparable, proponemos ceñirnos a aspectos objetivos como son el intercambio de una mercancía económica de forma ilegal y oculta entre actores interdependientes para hablar de corrupción, y de apoyo político a cambio de una distribución focalizada de los recursos, de forma alegal y pública para hablar de clientelismo. De lo contrario, los estudios empíricos se encontrarán con grandes dificultades de operacionalización y detección de mecanismos cuando se trata de cuidar al electorado o cuando la mera preferencia por una opción puede ser categorizada como "corrupción», concepto que de este modo deviene una suerte de significante vacío que pretendiendo abarcarlo todo acaba por no explicar nada con mínimo rigor. Por todo ello, el clientelismo no puede ser categorizado como un «subtipo» de corrupción, sino un fenómeno que en ocasiones se articula con ella, especialmente cuando sirve para proveer de financiación a las redes de favores políticos.

\section{CONTEXTO Y PLANTEAMIENTO DE LA INVESTIGACIÓN}

\section{Características del clientelismo en España}

La movilización electoral con estrategias clientelares en Espańa es baja si la comparamos con otros países del sur de Europa (Kopecký y Scherlis, 2008: 367; Blakeley, 
2001; Hopkin, 2001: 133), pero tampoco está erradicada entre los grandes partidos, con líderes locales que controlan las redes clientelares (Heywood, 1996), con especial prevalencia en determinadas áreas rurales como el interior de Galicia, donde el caciquismo ha sobrevivido hasta la democracia actual (Cinar, 2016: 84).

El clientelismo en España ha seguido un proceso de deterioro y desactivación análogo al de otras democracias europeas (Blakeley, 2001: 94), a pesar del bajo nivel de asociacionismo en la década de los setenta y ochenta, que dificultó la solidaridad horizontal y la acción colectiva para que los individuos se defendieran del clientelismo en regiones españolas como Galicia, Andalucía, Islas Canarias y provincias de Castilla (Hopkin y Mastropaolo, 2001). Con la llegada de la democracia, algunos partidos concentraron sus esfuerzos en fortalecer redes clientelares que conectasen los votantes con las nuevas instituciones democráticas. La necesidad de crear organizaciones fuertes en un sistema de partidos estable propició en algunas fuerzas políticas la intermediación entre el sistema político y la sociedad, y entre grupos de interés y las instituciones en una sociedad civil débil después de casi cuarenta ańos de dictadura de Franco (Gómez y Verge, 2011: 316).

Así, las condiciones iniciales que sostuvieron al clientelismo en España fueron dinámicas en conflicto: a) la demanda débil de clientelismo por parte de la sociedad civil debido a la creciente autonomía de las asociaciones y la capacidad del Estado para imponer la Ley, y b) el aumento de los recursos disponibles en los Gobiernos regionales ${ }^{1}$ y la fortaleza de los partidos para intermediar entre el Estado y la sociedad (Blakeley, 2001: 95). Cabe destacar que el saldo de estas fuerzas es negativo para el clientelismo, sin perjuicio de que el fenómeno esté presente en enclaves rurales y más asentado en unas regiones que en otras, con predominancia del Partido Popular (PP) en Galicia a través de oportunidades privadas de empleo (Pantín, 2019), donde con anterioridad la UCD «reclutó a individuos de prestigio y autoridad durante el régimen predemocrático para explotar la capacidad de movilización de sus redes» (Hopkin y Mastropaolo, 2001: 162), o en Andalucía a través del Plan de Desempleo Rural (PER) en manos de los alcaldes (Corzo, 2002).

\section{Caracteristicas de la corrupción en España}

Los gobiernos locales concentran buena parte de la corrupción que busca el lucro personal al aprovechar las deficiencias del diseño institucional español (García et al., 2014), con especial protagonismo de la regulación urbanística en municipios afectados por el boom inmobiliario (Jiménez, 2009).

Las evidencias empíricas parecen demostrar que la corrupción, en sentido estricto, representa un fenómeno residual entre funcionarios y ciudadanos (pago de

1. Otras investigaciones destacan el buen diseño de la descentralización española como freno a la política de patronazgo. Véase Gordin (2009). 
sobornos para recibir servicios). La Comisión Europea, en su informe sobre la Corrupción de 2014, limita la frecuencia para España del pago de sobornos de ciudadanos a funcionarios -en el último año- a un $2 \%$, frente a un $4 \%$ de media en la $\mathrm{UE}^{2}$. A la vista de los datos, la hipótesis de una corrupción generalizada entre ciudadanos y funcionarios en España no resulta plausible. El diagnóstico es más confuso si se contrastan con la alta percepción de corrupción en España, como muestran el Índice de Percepción de la Corrupción de Transparencia Internacio$\mathrm{nal}^{3}$ y las encuestas del Centro de Investigaciones Sociológicas ${ }^{4}$. Pero entonces, ¿dónde reside la corrupción? Todo parece indicar que la corrupción dominante en España es política y de dos tipos fundamentales: a) la corrupción malversadora y extractiva de los recursos públicos por parte de políticos y sus cómplices, con la ayuda de élites empresariales estrechamente vinculadas a las contrataciones públicas, y b) la basada en los abusos, arbitrariedad y prevaricación para beneficiar a agentes clave que puedan cooperar en el objetivo compartido de conservar el poder en el seno de los partidos y controlar las instituciones públicas. Así, ambos tipos de corrupción pueden responder a motivaciones distintas y conceptualizaciones separadas, pero comparten canales, redes y contactos para servir a los propósitos de ambas tipologías.

TABLA 2.

MATRIZ CUADRADA DE COMBINAR EL FENÓMENO CLIENTELAR Y CORRUPTO

\begin{tabular}{|c|c|c|}
\hline & Clientelismo & No clientelismo \\
\hline \multirow{3}{*}{ Corrupción } & Corrupción de partido oculta. & $\begin{array}{l}\text { Extracción de los recursos para } \\
\text { beneficio privado de forma oculta. }\end{array}$ \\
\hline & \multirow{2}{*}{$\begin{array}{l}\text { Ilegalidad para beneficiar a los apoyos } \\
\text { políticos. }\end{array}$} & Motivación apolítica. \\
\hline & & $\begin{array}{l}\text { Abuso del cargo para fines } \\
\text { estrictamente personales. }\end{array}$ \\
\hline \multirow{2}{*}{$\begin{array}{l}\text { No } \\
\text { corrupción }\end{array}$} & $\begin{array}{l}\text { Estrategia para la distribución de los } \\
\text { recursos públicos con criterios de } \\
\text { eficiencia electoral. }\end{array}$ & $\begin{array}{l}\text { Política programática, pública, } \\
\text { pluralista y codificada. }\end{array}$ \\
\hline & $\begin{array}{l}\text { Manifestación de preferencias } \\
\text { focalizadas. } \\
\text { Intercambio de favores alegales. }\end{array}$ & $\begin{array}{l}\text { Ausencia de rendición de cuentas } \\
\text { clientelar y de motivaciones } \\
\text { corruptas. }\end{array}$ \\
\hline
\end{tabular}

Fuente: elaboración propia.

2. Véase los datos para España del «EU Anti-Corruption Report» en: http://bit.ly/2MOehzi.

3. Véase el informe de Transparencia Internacional en: http://bit.ly/2Nj4dh8.

4. Véase la percepción de los principales problemas en España del Centro de Investigaciones Sociológicas en: http://bit.ly/2pfoA6z. 
La confusión empírica justifica que ambos fenómenos deben analizase con mayor precisión. Para ello, en esta investigación se acude a estudios de caso que den cuenta «de las razones que explican la frecuente superposición del clientelismo y corrupción en la vida real» (Máiz, 2003: 5). Lo que este artículo aborda no consiste, pues, en la corrupción sin motivación política (enriquecimiento), sino en la corrupción del proceso político que atañe a partidos y las luchas externas e internas por el poder. Para ello se diferencia en la tabla 2 entre el clientelismo, la corrupción, el clientelismo corrupto y la ausencia de ambos en la actividad política.

El estado de la cuestión sugiere la siguiente pregunta de investigación (PI) (Máiz, 2003, 2005): «¿Cuáles son las causas y contextos para que las redes clientelares en Galicia acaben desarrollando prácticas corruptas?» La respuesta a esta pregunta requiere aportar datos empíricos sobre el solapamiento de ambos fenómenos en la práctica clientelar. Nuestro análisis quiere mostrar por qué para facilitar y reproducir los intercambios clientelares propios del clientelismo de partido en ocasiones se requiere de intercambios corruptos, lo cual altera algunos rasgos básicos que le caracterizaban en la literatura al clientelismo, en concreto: recursos empleados, actores implicados y cumplimiento de la legalidad.

Para responder a la PI, se formula las siguientes hipótesis:

- H1. El acceso a una posición política por métodos clientelares implica un coste, para satisfacer a sus valedores en forma de corrupción o clientelismo.

- H2. A pesar de su diferenciación teórica, la concurrencia en algunos escenarios de clientelismo y corrupción se debe a que forman parte de un mismo sistema político informal.

- H3. La insostenibilidad en el tiempo de la rendición de cuentas clientelar obliga a los patrones a emplear prácticas corruptas.

\section{Método y fuentes}

El material empírico se basa en tres estudios de caso de tres patrones locales, cuya trayectoria política se inicia en el período predemocrático y llegan a alcanzar altas cuotas de poder dentro de su partido. Son tres casos representativos de político clientelar que supieron poner su capital social a disposición del partido y este último, a su vez, su control de los recursos públicos a disposición de los clientes/votantes. Los tres casos son paradigmáticos por la extensión de las redes clientelares locales, conocidas mediante su trascendencia mediática y judicial, lo que nos ha permitido realizar observaciones cualitativas sobre la evolución de redes capitaneadas por un patrón, con especial atención al proceso sociopolítico, a los mecanismos empleados y la utilización de métodos corruptos.

El trabajo de campo se realizó a lo largo de varios años y cubre desde los inicios del período de transición política hasta el año 2015. Consistió en entrevistas, vaciado de 
fuentes secundarias, noticias de prensa, documentación, autos e informes judiciales. La práctica etnográfica sobre el terreno y la observación participante ha permitido diversificar los puntos de vista (Auyero, 1999; George y Bennet, 2005) y acceder a información muy detallada compartiendo con actores clave su experiencia en un partido de la oposición, pidiendo un favor, apoyando a un político después de haber recibido un beneficio, escuchando las historias de fuentes locales, el relato de organizaciones excluidas de las bolsas de subvenciones por la afiliación de alguno de sus miembros o a los afectados por figurar en las listas de un partido de la oposición.

Durante los primeros pasos de la investigación se asumió que el sesgo de selección no aleatoria de los casos era una barrera insalvable, debido a la irregular implantación territorial de las redes y a la necesidad de buscar tanto casos relevantes como ricos en información para una comparación cualitativa (Yin, 2003). Así, aunque los efectos de la política clientelar sean visibles, la naturaleza oculta de las prácticas corruptas proveedoras del favor no constituye una barrera menor. El acceso a la información, la realización de entrevistas, la práctica etnografía y lograr que los sujetos se expresen con libertad para llegar a ser informantes clave, la selección de documentación fiable y contrastada, dependen de "conseguir contactos» en partidos, asociaciones vecinales, medios de comunicación, sindicatos y ámbito judicial, por lo cual resulta necesario acudir a lugares en los que la manifestación del fenómeno sea una evidencia social reconocida.

El caso 1 corresponde a una diputación provincial volcada en el subsidio político de los municipios rurales de su circunscripción, y los caso 2 y 3 representan al ayuntamiento de dos municipios de tamaño medio. En una muestra cualitativa de este tipo, los criterios de calidad están fijados por la saturación teórica. El marco territorial donde operan las redes seleccionadas está situado en la Comunidad Autónoma de Galicia (España), y comparten por ello una misma comunidad política, histórica, cultural y territorial que facilita la analogía y la comparación controlada.

\section{ANÁLISIS DE LOS CASOS: DESDE EL CLIENTELISMO HACIA LA CORRUPCIÓN}

A continuación se lleva a cabo un breve análisis descriptivo de los bienes de intercambio concretos y documentados que fueron empleados por los patrones JB (caso 1), JC (caso 2) y JLB (caso 3) para permanecer en el poder de sus municipios y de la provincia, gestionando sus potentes redes de clientes y brokers locales.

\section{La patrimonialización del empleo público}

Los estudios de caso muestran como el privilegio de acceder a un puesto de trabajo a través de los contactos en las redes clientelares se reserva a lo que la literatura llama "patronazgo» (Stokes et al., 2013), es decir, a los miembros destacados del partido, 
concejales o familiares de estos. En los casos del clientelismo analizados, para los clientes-votantes (vote buying) se destinan los puestos de trabajo temporal rotatorios que protagonizaron, por ejemplo, las contrataciones de baja cualificación, de tres y seis meses en la diputación provincial (caso 3) de un territorio con un mercado laboral sin oportunidades y poco competitivo bajo criterios objetivos de cualificación y mérito 5 .

Las implicaciones psicosociales de este tipo de favores son muy importantes: el agradecimiento hacia el patrón refuerza los lazos de confianza personalizada (trust focalization) (Roniger, 1990: 16), que llega a alcanzar la pleitesía, dado que el puesto de trabajo puede implicar repercusiones muy beneficiosas para el individuo que lo recibe y su entorno. A consecuencia de ello, el agradecimiento al boss se ve reforzado y amplificado a través de las redes de carácter familiar: los padres del beneficiado, su pareja o sus hijos perciben el favor como propio y entran a formar parte de las huestes del patrón. Este efecto multiplicador construye un habitus social claro: los beneficios de ser leal al patrón mediante una experiencia directa y los perjuicios de ser opositor. Correlativamente a la confianza focalizada, se corresponde una paralela producción política de desconfianza generalizada en los otros clientes y en las instituciones democráticas.

Las dinámicas en los sistema de favores están atrapadas en una path dependecy: el círculo vicioso de clientelismo-corrupción-clientelismo se retroalimenta para financiar la red de recursos, tanto materiales como intangibles. Esto se observa en el caso 2, donde el alcalde JC fue acusado de prevaricación, malversación de fondos y tráfico de influencias por las irregularidades cometidas en la contratación de sesenta trabajadores municipales, los cuales poseían vínculos directos con el partido de Gobierno y/o con familiares de agentes electorales (patronazgo). Estos son elementos necesarios para la movilización durante la campaña y alcanzar el gobierno local, lo cual implicaba la creación continua de puestos de trabajo dentro de la estructura administrativa del Ayuntamiento y un crecimiento continuo de los gastos de personal ${ }^{6}$.

Tal y como recoge una crónica periodista en un conocido diario, la lista de personal contratado directamente por JC — popularmente conocidos como «los enchufados de JC»-, alcanza la cifra de 200 sin oferta pública ni concurso ${ }^{7}$. Desde un punto de vista racional de la gestión pública interesa adecuar las necesidades institucionales con el perfil del contratado y seleccionar a aquellos mejor formados para el puesto; en cambio, desde un punto de vista racional de la política clientelar interesa adecuar las necesidades electorales con el sujeto contratado y seleccionar a aquellos más influyentes. Del análisis del perfil y manifiesta vinculación de los clientes «colocados», resulta notorio la baja cualificación exigida para los puestos (auxiliares, administrativos, porteros, vigilantes, peones de obra, conserjes, puestos ambiguos como "ayudante de»,

5. Para profundizar en el estudio de caso acudir a Pantín (2019).

6. Para profundizar en el estudio de caso véae (Pantín, 2019).

7. Véase los datos sucesivos en el anexo de (Pantín, 2017), disponible en: http://eprints.ucm. es/45524/. 
«personal polivalente»), etc. y la presencia de familiares del patrón JC, concejales y familiares, candidatos y familiares de candidatos o interventores de mesa. El establecimiento de vínculos de dependencia con estos agentes, crea incentivos evidentes para proteger y velar por la continuidad del patrón.

El conocido como "caso de los enchufes masivos» del presidente de la Diputación JLB (caso 3) será empleado como muestra empírica del funcionamiento de la contratación clientelar multinivel (Pantín, 2019) de una máquina local que toca distintas esferas de poder en un entorno de falta de oportunidades laborales. La estrategia desempeñada por el partido de la oposición en la Diputación incluirá la vía judicial como método de hacer oposición, como alternativa a los escasos resultados de la política de denuncia pública en los medios de comunicación y en el pleno de la institución provincial. Por ello, se motivó una denuncia ante la Fiscalía seleccionando a ciento cinco trabajadores que fueron contratados por el ente público dos meses antes y dos meses después del congreso de 2010, donde JMB, el hijo del antecesor en el cargo, fue elegido presidente del partido en la provincia. La selección directa de los trabajadores sin concurso supuso irregularidades varias en los procesos administrativos de los contratos, a lo que la Fiscalía reaccionó en forma de querella por el empleo reiterado de un procedimiento de contratación contrario al ordenamiento jurídico, la falta de publicidad sin informe del secretario de la institución, etc. No se pronunció, sin embargo, acerca de los vínculos de los contratados con el partido de gobierno, origen de la denuncia, entre otros motivos porque es un derecho básico la no discriminación por ideología. De hecho, la oposición siempre definió la actividad como una estrategia política clientelar que entraba en conflicto con la legalidad. Algo distinto a la corrupción.

Las declaraciones de testigos e imputados ante el juez de instrucción ${ }^{8}$ revelan un factor clave del funcionamiento de la red clientelar: casi la totalidad de los trece alcaldes con vecinos entre los ciento cinco «agraciados» reconocieron al juez que eran ellos los que sugerían al presidente JLB a quién tenía que contratar, procedimiento también recogido en la declaración del jefe de recursos humanos, lo cual, les confiere a estos alcaldes el rol de intermediarios de la red clientelar. En el escrito, el fiscal pregunta a un regidor por qué recomendó al patrón contratar a diez vecinos concretos, a lo que el regidor contesta "porque estaban en el paro»; el fiscal insiste y le pregunta si eran los únicos vecinos en el paro, a lo que el alcalde, con total normalidad, aclara que no, pero «era la gente que venía junto a mí a pedir». Otro alcalde describió la percepción de los demás regidores, y la de él mismo del presidente provincial: «Era un hombre solidario con nuestras emergencias", declaró ante el fiscal.

La acusación de la oposición insta al juez a que solicite la cuantificación presupuestaria de los ciento cinco contratos, tarea que corresponde al servicio de intervención de la Diputación, con el objetivo de sumar un nuevo delito a JLB. Sin embargo, la labor de intervención del ente público estaba supervisada por el hijo del presidente de una

8. Para este y datos sucesivos del artículo véase el anexo con el trabajo de campo en Pantín (2017), disponible en: http://eprints.ucm.es/45524/. 
diputación vecina, por lo tanto hombre fiel, que lo contrató gracias a la flexibilidad de la ley para que los presidentes de las diputaciones contraten, ellos mismos, a quienes los van a intervenir. Cuando llega este escrito el juez lo descarta como prueba de intervención por imprecisión, lo cual vuelve a mostrar cómo la red clientelar se preocupaba de controlar los resortes administrativos, dificultando de esta manera la investigación judicial.

En el mismo escrito la acusación requiere la certificación de «la situación actual de las 105 personas identificadas en la querella en relación a si mantienen vinculación laboral, administrativa o de algún tipo con la Diputación Provincial», o «cualquiera de sus organismos públicos de ella dependientes». Está vía tampoco prosperó y hubiera resultado de no escaso interés porque demostraría el funcionamiento continuo de la maquinaria clientelar. Cabe destacar que todas estas maniobras internas fueron en aras de un objetivo clientelar poco disimulado, donde se detectaron prácticas irregulares y conexiones con la corrupción.

En su último día como presidente de la Diputación, JLB fue despedido por cientos de trabajadores de la institución entre aplausos, en agradecimiento por sus servicios a las puertas del palacio provincial. Dos años después algunos de ellos acabarían declarando ante el juez, eximiéndose de cualquier tipo de intervención en el proceso de contratación de personal. Otros contradijeron su versión y describieron la permanente intervención de JLB en la selección curricular.

En el verano de 2014, y según recoge la sentencia, JLB fue condenado por contratar "a quién le vino en gana» como si fuese "una empresa privada», un total (demostrado) de ciento cuatro personas, saltándose la normativa de contratación pública "como quien dispone legítimamente de algo privado». La condena al regidor fue de nueve años de inhabilitación para desempeñar un cargo público, sentencia que quedó sin efectos, pues ya se encontraba retirado. La condena en firme llegó un año más tarde, y niega la petición de la acusación popular de que el exbarón provincial devolviese los casi 700000 euros en concepto de responsabilidad de civil, suma que representaban las ciento cuatro contrataciones. El magistrado rechazó la petición, entre otros motivos porque JLB no tuvo «enriquecimiento personal»; esto justifica una vez más la diferencia entre clientelismo, corrupción al servicio del clientelismo y corrupción al servicio del patrimonio privado. Estos escándalos fueron recurrentes en los medios de comunicación que, como resignadamente reconoció después algún responsable de la oposición, su difusión solo servía para reforzar la reputación del patrón de "conseguidor» y hombre generoso.

La modalidad de clientelismo destinada a beneficiar a los miembros del partido para mantener cohesionado al aparato también se refleja en los ciento trece concejales electos del PP, que a fecha de 2011 son personal de la Diputación, lo cual representa el $20 \%$ de los concejales del PP en la provincia. Esta financiación a intermediarios o agentes electorales permite al patrón ser reelegido presidente de la Diputación y mantener siempre a su disposición el engranaje de la máquina, garantizando así una alta movilización en las elecciones generales y autonómicas. En esta cifra no se incluyen los 
familiares de concejales, que aumentarían el porcentaje de beneficiarios de manera significativa.

\section{El patrón clientelar como controlador de la administración}

Como hemos visto, los brokers son intermediarios en la relación clientelar y demandan a sus patrones recursos para repartir en la red. Por ejemplo, el patrón del caso 1 desempeñaba su papel de intermediación a través de sus vínculos con las famosas «autoridades», conseguía recomendaciones en el servicio militar y contactos en la provincia y en los ministerios para realizar negocios. También empleaba la permisividad normativa como mercancía clientelar: exenciones tributarias, anulación de multas de tráfico, permisos informales de edificación (según la conocida fórmula «ti vai facendo» — «tu vete haciendo $[\ldots]$ —) o la agilización o eliminación discrecional de trámites administrativos a la clientela.

Una muestra empírica de la imbricación progresiva entre prácticas corruptas y clientelistas son los primeros pasos en la actividad política de JB, patrón del caso 1, quien comenzó tejiendo una red local de influencias y como concejal durante el tardofranquismo llegó a la alcaldía con una de esas maniobras que llevan al político clientelar a convertirse en un hombre de negocios si estos dependen más de la regulación que del mercado. JB compró terrenos protegidos y demandados por los especuladores urbanísticos de la zona, ejerciendo así una función de intermediador entre los constructores y el Ayuntamiento. Esto lo posicionó para ser nombrado regidor por el gobernador civil en 1975, gracias a la recomendación de un famoso constructor de la provincia; una vez asentado en el consistorio, donde permaneció varios ańos, los hombres de negocios dependerían de él y este de ellos para ofrecer favores a la clientela.

Así se gestó el proceso que derivó desde el clientelismo hacia la corrupción: JB apoyó toda irregularidad urbanística que sus contactos y clientes le demandaron (urbanizaciones costeras sin licencia, apropiación de terrenos comunales, edificaciones en la playa, etc.), pero también con muy extenso repertorio de prácticas delictivas al evitar paralizar obras ilegales o, por ejemplo, cuando permitió la explotación de una cantera ilegal en terrenos municipales sin licencia, sin subasta y sin proyecto ni informes técnicos). Como paradigma de colaboración corrupta público-privada está el caso de la privatización de suelo de incalculable valor paisajístico, con la colaboración de distintos ministros. Especialmente, JB le debió el favor de su cargo de alcalde al citado constructor de la provincia, devuelto con la concesión de obra pública (construcción de la traída de aguas), por supuesto bajo flagrantes irregularidades que, sin embargo, dada su agilidad y precocidad sirvieron a JB para agrandar su fama de «conseguidor» y «buen gestor». Ante las denuncias de la oposición, el patrón respondió que la oposición quería impedir con «formalismos» obras importantes para los vecinos.

En el caso 2 se observan operaciones análogas. El alcalde JC exigía la tramitación previa de los procedimientos con la Administración desde su propio despacho. En convivencia con los empresarios de la construcción, el alcalde JC creó una tupida red 
de intereses permitiendo la edificación indiscriminada en su municipio sin atención alguna a las normas vigentes de planeamiento y procediendo a su conculcación cuando era preciso. Se trataba de dar facilidades y remover obstáculos a los constructores a fin de que estos devolviesen el favor.

Las relaciones entre Ayuntamiento y empresas privadas comenzaron a estrecharse a fin de crear un nuevo soporte clientelar que diera cabida a los numerosos parados que acudían al despacho de JC. El mecanismo pasaba por conceder ventajas fiscales y permisividad a empresas que generaban numerosos puestos de trabajo. Varias de estas, ubicadas en el caso 2, obtuvieron por parte del Ayuntamiento rápidas licencias de apertura y ventajosas tasas y exenciones fiscales a cambio de reservar puestos de trabajo para que JC pudiese colocar a sus seguidores.

Otro ejemplo de interacción entre política y mundo de los negocios para instrumentalizar los puestos de trabajo al servicio de la red clientelar puede ser intuido atendiendo al proyecto fallido de instalación de una universidad privada en la localidad. El patrón local JC ofreció al empresario laxitud fiscal y urbanística a cambio de poder distribuir desde el Ayuntamiento becas de estudio y contar con ventajas para los vecinos de la localidad, una bolsa de puestos de trabajo lista para ser explotada con la intermediación del patrón (presidente autopropuesto de la comisión de becas).

El poder que el Ayuntamiento ejerció en el caso 2 sobre la clasificación y calificación del territorio urbanizable, las licencias de construcción y las normas que regulaban todo el ordenamiento urbanístico, son fuentes de las que los políticos extraían importantes recursos que poner en juego a la hora de establecer la red clientelar con los votantes. En paralelo, los intereses de constructores y promotores inmobiliarios abiertos a la corrupción confluyeron con las demandas de los vecinos, estableciendo una serie de relaciones que a todos beneficiaban desde el punto de vista individual, y cuyo nexo en común e intermediador - broker - era el alcalde.

El estudio de la aplicación selectiva de la normativa urbanística y otras actuaciones ejecutivas desde el Ayuntamiento presenta claras pruebas del modo en que estos factores operaban para diseñar, construir y mantener una red de influencias y un flujo de ingresos y votos hacia el patrón. En muchos casos, la práctica habitual era solicitar una licencia de construcción de galpón o cobertizo por ser la más económica, y construir luego una vivienda de dos o más plantas. También era frecuente que la licencia se concediera con posterioridad a la construcción si el vecino advertía previamente al alcalde, creándose a resultas de ello estrechos vínculos de dependencia personal y política. Cabe destacar que estas dinámicas de gestión particular entre conocidos son frecuentes en la política municipal de pequeñas localidades, donde la red controlada por el patrón protagoniza intercambios corruptos por un lado e intercambios clientelares por otro.

En el caso 3, la estrategia de JMB, hijo del viejo barón provincial —que en la actualidad ocupa todos sus cargos_ pasaba por «adelgazar» la Administración a través de privatizaciones y subcontrataciones de servicios. A JMB no le gustaba hablar de "política», sino de "gestión", y empleaba un nuevo sistema clientelar que consistía en el desmantelamiento de algunos servicios que antes proveía la Diputación, ahora trasladados a empresas y otros organismos semipúblicos. La conocida externalización de 
servicios: privatizar la gestión, pero manteniendo la financiación pública con el objetivo formal de mejorar la «eficiencia», lo que acabó desvinculando al político de la responsabilidad de jure en las contrataciones de personal para que estas las realizaran empresas concesionarias de los servicios. Así escapa de facto, a su vez, de la labor fiscalizadora de la Administración que recae sobre todo gasto con recursos públicos, y genera un nuevo campo para el desarrollo de la corrupción y el clientelismo, también fuera del control democrático de la oposición en los plenos.

Los tres casos analizados no estuvieron dominados por las prácticas corruptas, aunque en no pocas ocasiones de corrupción ha servido a fines clientelares y en otras a fines personales. El minucioso trabajo de etnografía realizado mostró que los residentes en áreas de clientelismo tenían una abultada experiencia en el hábito clientelar, no así en el imperio de la ilegalidad y la corrupción. Parece insostenible que la corrupción domine todo acto político durante décadas sin que la justicia actúe. Tampoco parece posible que la corrupción gane, por sí misma, mayorías electorales. La sociedad reconocía el clientelismo como un fenómeno político público y notorio cuando la inversión en el mantenimiento de viales se dirigía a determinadas parroquias o la agilidad institucional era más sensible a las reclamaciones de determinados sujetos (votantes). Por ello, se insiste una vez más en que la corrupción ha sido un instrumento para servir al clientelismo como mecanismo de rendición de cuentas políticos-votantes.

Se podría concluir que la consolidación de un patrón implica tener a su alcance un gran volumen de recursos económicos públicos y privados, capacidad reguladora, potestad ejecutiva en una institución, capital social con particulares, empresas y administraciones, capital simbólico respecto a la ciudadanía y una posición en el partido garante de estabilidad política. Con todos estos recursos contaban los tres patrones de nuestro estudio, algunos de los cuales resultaron adquiridos y mantenidos empleando métodos corruptos. Esta situación provoca que los patrones incurran en acciones ilegales y de este modo, lo que comienza como un conjunto de operaciones clientelares y nepotismo para mantenerse en el cargo, desemboca en la corrupción como mecanismo de autorrefuerzo: prevaricación, tráfico de influencias y malversación de fondos públicos, y más tarde en problemas judiciales que, también en los tres casos analizados, los desalojan del poder.

\section{DISCUSIÓN DE LOS RESULTADOS: LA SUPERPOSICIÓN DE CLIENTELISMO Y CORRUPCIÓN}

Las descripciones vertidas en la escueta extensión de este artículo han priorizado mostrar la deriva corrupta y corrupto-clientelar de los patrones. Sin embargo, el clientelismo y patronazgo fueron otras estrategias cotidianas en su actividad, más frecuente si cabe, donde la discrecionalidad administrativa y el gasto público focalizado fue habitual, conocido y respaldado en las urnas como una rendición de cuentas más provechosa que las políticas públicas pluralistas y universales. Así, la mera articulación de preferencias que revierta -o beneficie — a uno mismo no puede ser calificada como 
corrupción si no se desea caer en un concepto demasiado elástico. La corrupción requiere un abuso del cargo para beneficio privado, la acción política convertida en un fin netamente personal. Si un político prioriza el gasto en un barrio de forma pública y notoria, puede estar incurriendo en prácticas clientelares, pero no en corrupción, aunque se beneficie de los votos de esa zona. Si un político se enriquece simulando un concurso público — de forma oculta — , hablamos de corrupción. Si un político utiliza su capacidad regulatoria para beneficiar a un sector particular a cambio del voto de los sujetos beneficiados, estamos hablando de clientelismo corrupto. No basta con que un agente salga beneficiado de su actuación en el cargo para que se produzca corrupción. Tampoco se produce clientelismo si no existe un control de los votos recibidos mediante intercambio directo de favores por votos.

En los casos analizados el fenómeno del clientelismo y la corrupción comparten circuitos y actores en determinadas circunstancias, pudiendo ser ambos fenómenos interdependientes en el plano empírico. La corrupción no deja de relacionarse con la política porque depende de las competiciones electorales y del control interno de los partidos para continuar accediendo a puestos de decisión que permitan seguir extrayendo dinero público hacia un patrimonio privado. Lo que aquí se ha intentado es describir la superposición de ambos fenómenos en una serie de casos donde la práctica clientelar y corrupta produce un fenómeno híbrido de circuitos traslapados (nested circuits) que imposibilita establecer fronteras empíricas claras; de ahí la necesidad de una nueva categoría de análisis conceptual: el clientelismo corrupto.

La ambigüedad y zona gris entre fenómenos se manifiesta en las dificultades de los tribunales para demostrar corrupción, por lo que la Fiscalía opta por la estrategia de investigar irregularidades y defectos de procedimiento cuando la extracción sirve al clientelismo corrupto. La política de secuestro de la Administración para focalizar el gasto acaba consistiendo en «errores» de garantías sin una motivación corrupta clara que no pasa de una sentencia de inhabilitación. Así, los efectos de la tutela judicial (Dahl, 1989) que revierte los resultados electorales, expulsando de la vida política a estos patrones, merece ser estudiada en profundidad, toda vez que un político públicamente clientelar genera mayor rechazo en los tribunales que en su bolsa de votantes, donde mantiene un alto grado de fidelidad, incluso cambiando de partido o creando candidaturas independientes, que arrastran buena parte de su clientela en su itinerario.

¿Por qué la política clientelar incorpora métodos corruptos? Si bien el clientelismo no requiere de corrupción para manifestarse, su articulación se explica a) por las dependencias y deudas pasadas contraídas en el momento de acceder al cargo; b) por compartir actores, circuitos y canales de intercambio retroalimentados, y c) por la demanda creciente de recursos para distribuir y satisfacer a las redes de receptores. Estos factores representan un hilo conductor a lo largo de los tres casos estudiados, donde los patrones parecen dirigir su gestión con el criterio de generar complicidades con agentes en puestos clave (capital social), y consolidar su reputación de conseguidor (capital simbólico).

El análisis de los hechos relatados se desprende la veracidad de la primera hipótesis cuyo planteamiento obtiene el respaldo de los hechos observados en el caso 1, cuando 
el concejal JB comenzó a intermediar en los negocios de constructores de la zona a través de procesos ilegales para que le facilitasen el nombramiento como regidor, financiasen sus campañas, etc. Después, este se vio en deuda, que satisfizo mediante la exención arbitraria de la normativa municipal y el pago de licencias y tributos. La misma lógica ha sido descrita en el caso 3 con el nombramiento del presidente provincial del partido, donde contrae una deuda con los compromisarios que satisface con las contrataciones de personal, incurriendo el regidor en irregularidades y corrupción.

En lo que se refiere a la segunda hipótesis, la concurrencia de redes clientelares y redes corruptas tiene que ver con que comparten el mismo tipo de actores: a) algunas estructuras como partidos, instituciones y organismos públicos, asociaciones, clubs o empresas, y b) roles individuales, como afiliados en sedes locales de partidos, delegados o políticos locales (brokers), particulares con intereses, buscadores de rentas y empresarios dependientes de la regulación y los concursos públicos. Los alcaldes, concejales, funcionarios o empresarios vinculados al sector público son contactos que permiten un funcionamiento eficiente del sistema clientelar para movilizar durante las elecciones, agilizar trámites, transferir recursos dirigidos, sortear procesos burocráticos, influir en la toma de decisiones, financiar campañas, etc. En ocasiones, el origen de estas lealtades de agentes clave deja una huella corrupta, y siembra confusión en el análisis de dos fenómenos diferenciados y autónomos en el debate conceptual, si bien en ocasiones superpuestos en la vida real. La explicación que confirma, para los casos estudiados, la segunda hipótesis se muestra en la figura 1 que representa un bucle, con los políticos-patrones en el eje del sistema, que reciben votos de los electores a cambio de su intermediación con las instituciones (local, provincial, autonómica o central) para dirigir sus recursos, a menudo facilitados a través de canales corruptos con las instituciones o con empresas vinculadas al sector público.

De esta forma, desde una dimensión sistémica las redes clientelares/corruptas se autorrefuerzan mediadas por políticos que intervienen en las conexiones entre recursos, formando un sistema dinámico y cooperativo que deriva en una estructura compacta y muy eficiente para que cada actor satisfaga su demanda y oferte el bien que controla.

¿Por qué se confunde la manifestación del clientelismo y la corrupción? Nuestro argumento es que en ocasiones las redes corruptas invierten en clientelismo para conservar su acceso al poder político. Y viceversa, políticos clientelares se ven obligados a acudir a métodos corruptos para satisfacer la cada vez más costosa demanda infinita de favores. Es decir, por una doble finalidad: a) fortalecer una red de beneficiarios que facilite las transacciones corruptas, y b) repartir favores y beneficios suficientes para comprar votos que sostengan su poder institucional. De este modo las redes clientelares verticales (político-votante) y las redes corruptas horizontales (político-funcionario-empresario corrupto) generan «afinidades electivas», esto es, se solapan y refuerzan mutuamente.

Cabe destacar que el fenómeno del clientelismo corrupto es una estrategia para gestionar el poder político, controlar las organizaciones y cohesionar los equipos y partidos, de tal modo que se facilite la gobernanza de las instituciones públicas bajo una paz 
Figura 1.

SOLAPAMIENTOS DE LOS CIRCUITOS CLIENTELAR Y CORRUPTO EN EL CAMPO DE LA COMPETICIÓN POLÍTICA ELECTOR

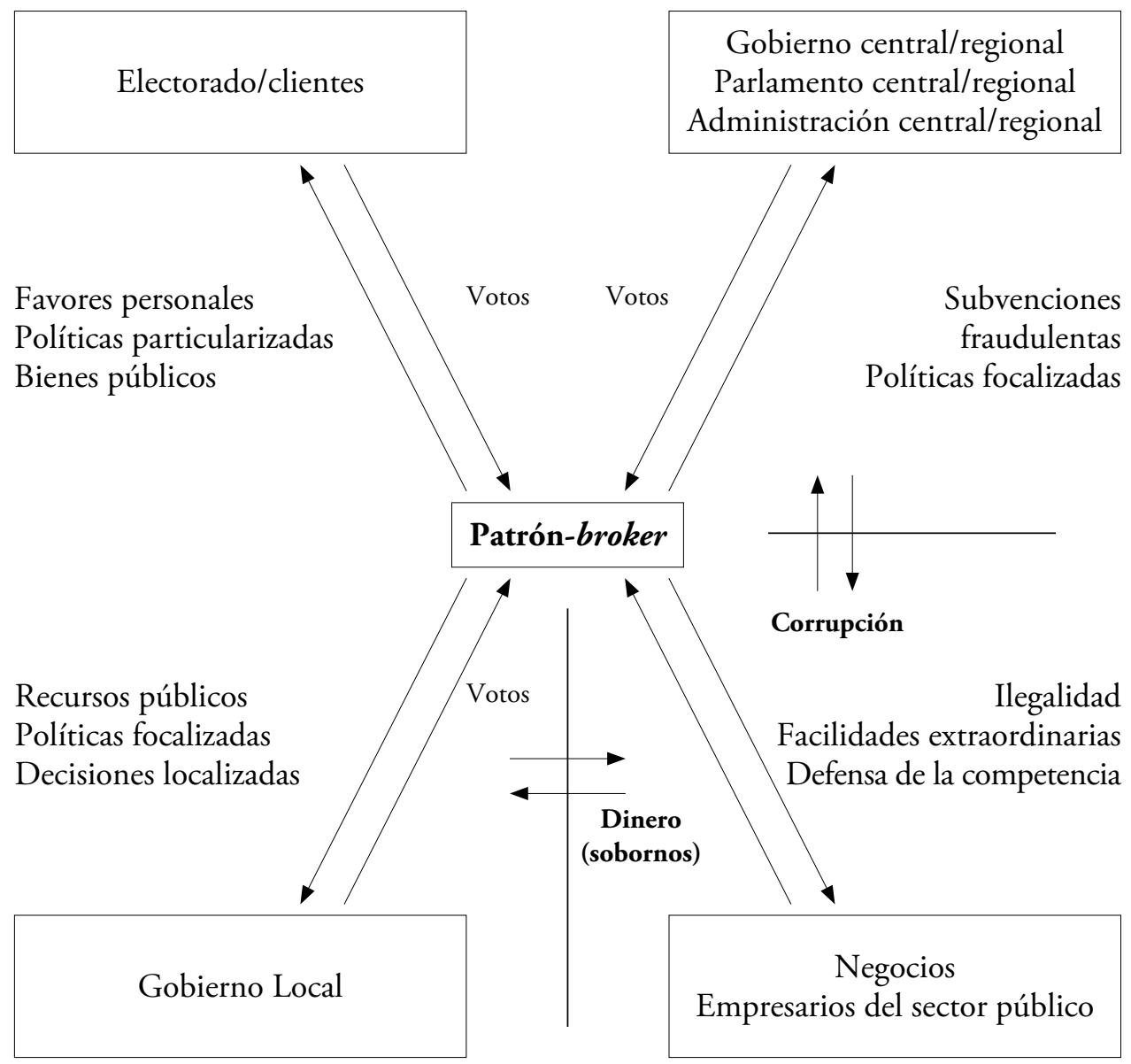

Fuente: elaboración propia a partir del análisis de casos.

corrupta, es decir, las transacciones corruptas como elemento pacificador e incentivador de la cooperación, la lealtad y la estabilidad de los partidos y Gobiernos.

La tercera hipótesis está prevista por la literatura: el desarrollo social y económico provoca un encarecimiento de los favores demandados por los clientes a cambio de apoyo electoral (Caciagli, 1996), cada vez más costosos y financieramente insostenibles. El análisis de los casos también muestra la insostenibilidad de la rendición de cuentas clientelar en contextos democráticos, debido a los incentivos para la asunción del riesgos, ilegalidad y corrupción. Esta tercera hipótesis encuentra un escenario acorde a su planteamiento durante la gran recesión y crisis económica desencadenada a partir de 
2008. Precisamente, en esos años de recorte presupuestario se produjo el proceso de "sucesión» del caso 3. La transmisión de la presidencia de la Diputación Provincial de padre a hijo, facilitada con los «enchufes masivos» a sujetos vinculados a brokers/delegados del partido que votarían en el congreso provincial, así como la privatización de servicios a empresas colaboradoras con las necesidades del partido, constituyen un modelo cualitativo equiparable a otros casos análogos. Para sumar mayorías y un partido cohesionado, el recurso de la corrupción fue la única alternativa para que la máquina política siguiese engrasada a pesar de la Ley de Estabilidad Presupuestaria y el descenso de la recaudación.

La previsión de la tercera hipótesis se refleja en la reacción de JB (caso 1) al fortalecimiento de los partidos de la oposición programática (que representaban una alternativa electoral plausible): una mayor intensidad en el uso de la ilegalidad. Por parte de JC (caso 2), la competición interna con otro patrón de su mismo partido (con el respaldado de las subvenciones prometidas por el presidente regional) coincide con una mayor asunción de riesgos y errores por parte del regidor.

Los períodos de crisis y transformación son muy reveladores para testar el comportamiento de la hipótesis. En los tres casos se ha observado que en período de crisis del sistema la estructura de incentivos fomenta que los políticos utilicen la corrupción como un mecanismo de autorrefuerzo y abaratamiento del clientelismo.

En estrecha vinculación con la tercera hipótesis, también se ha observado (especialmente en el caso 3) la subcontratación de los favores corruptos para evitar los riesgos de ilegalidad dentro las instituciones burocráticas. Las descripciones aportadas a lo largo del artículo resultan de sumo interés en el retrato de la institución clientelar adaptada a la nueva sensibilización de la opinión pública y los nuevos controles anticorrupción. Así, aprovecha los procesos de privatización y subcontratación de servicios para eludir responsabilidades en la distribución de favores. El trabajo de investigación mostró que los concejales de la oposición no tenían instrumentos para fiscalizar y exigir garantías cuando la gestión corresponde a una empresa y el proceso de contratación aparentemente cumple con la forma, a pesar de su intencionalidad espuria y ajena a la motivación exigible a un contrato público. Así, los patrones ofrecen favores corruptos a empresarios y, a cambio, estos ponen a disposición de los patrones financiación y puestos de trabajo en sus empresas que reciben los clientes, dibujando una relación triangular entre políticos-empresarios-clientes.

A diferencia del clientelismo clásico, el nuevo sistema corrupto-clientelar se distancia de una institución bajo cuyo paraguas se producían todas las contrataciones para evolucionar hacia una abigarrada y opaca red de organizaciones privadas proveedoras de servicios al sector público, que dificultan la investigación y observación del fenómeno. La nueva relación clientelar introduce la figura del empresario de lo público, un pacto horizontal entre iguales (patrón-empresario) que lo sitúa en el clientelismo corrupto y conceptualmente lo aleja del clientelismo vertical entre subordinados, propio de las relaciones patrón-cliente. En la práctica, se solapan las redes corruptas horizontales con las tradicionales redes clientelares jerárquicas. 


\section{CONCLUSIONES}

La corrupción clientelar es una categoría de análisis conceptualmente híbrida que incluye la ilegalidad, opacidad y los recursos de la corrupción para financiar los favores políticos de las redes clientelares, producto de la superposición empírica de redes clientelares verticales (patrón-cliente) con redes corruptas horizontales (político-político de negocios). Esto no contradice la teoría que diferencia ambos fenómenos, sin perjuicio de que puedan convivir y autorreforzarse. Cabe recordar que el clientelismo no es un subtipo de corrupción, sino un fenómeno autónomo que en determinadas circunstancias produce un cruce práctico y zonas solapadas de clientelismo corrupto, donde ambos fenómenos se yuxtaponen y devienen interdependientes: se trata de la obtención de fines clientelares con métodos corruptos. Estos argumentos parecen confirmar las hipótesis y que «no se trata de una mera coincidencia, sino de una asociación empírica deudora de un mecanismo o proceso subyacente» (Máiz, 2005).

El análisis del clientelismo corrupto despierta interés académico por dos motivos: el primero, para una correcta evaluación de los sistemas políticos que permita una mejora en el diseńo de nuestras instituciones; el segundo, para la teoría sobre partidos porque el ciclo clientelismo-corrupción-clientelismo puede explicar el comportamiento de los actores en algunos escenarios. Hemos visto cómo la estrecha línea divisoria y las frecuentes conexiones de las prácticas clientelares y corruptas dificulta una tajante separación analítica. Como fenómenos políticos conceptualmente diferenciados, pero que a menudo pueden llegar a solaparse, los hechos observados se vinculan parcialmente a ambos. La discusión teórica nos permite una diferenciación conceptual clara para la discriminación empírica entre a) clientelismo para distribuir recursos focalizados; b) corrupción con fines de enriquecimiento personal, y c) corrupción al servicio del clientelismo.

Desde el punto de vista de la desactivación del clientelismo, la relevancia de la corrupción reside en su capacidad reforzadora del sistema, que logra financiarlo y retrasar su deterioro en democracias avanzadas, aunque también puede provocar el declive del patrón clientelar cuando se le involucra judicialmente en escándalos de corrupción. El artículo proporciona descripciones sobre el fenómeno en España, donde apenas existen estudios para los comparatistas. También se ha explicado cómo los patrones utilizan a las empresas beneficiadas por la contratación pública fraudulenta para distribuir favores en las redes de favores, a modo de accountability clientelar con instrumentos de la corrupción. Entre los resultados más interesantes destaca la descripción sintetizada del sistema de la corrupción clientelar desde una perspectiva macroestructural que incluye a sus actores, controles y equilibrios, mecanismos y recursos de intercambio (figura 1). El modelo demuestra cómo funcionan estas peculiares «afinidades electivas»: el proceso de refuerzo mutuo, retroalimentación y solapamiento de redes clientelares y corruptas.

La rendición de cuentas clientelar representa un problema latente, pero con consecuencias directas sobre la calidad de la democracia, justificando su pertinencia como 
una variable independiente relevante en democracias avanzadas. Las obligaciones contractuales de los clientes con sus proveedores de favores (clientelismo electoral), las deudas de los políticos con aquellos que les colocaron en el puesto (patronazgo), y la necesidad de acceder a grandes recursos con sofisticadas técnicas de corrupción para financiar a la máquina clientelar o resolver conflictos de manera oculta, son factores que acaban por fortalecer el sistema y producir dependencia de la trayectoria.

El desarrollo económico, el crecimiento de las clases medias y urbanas y la competencia de la política programática (intercambio indirecto, mediado por ideologías) fortalecen la democracia, incentivan la demandan de políticas públicas, la competición ideológica y desprestigian la rendición de cuentas clientelar. El clientelismo, por otra parte, habida cuenta de la masiva inversión en redes de contactos y el constante flujo de recursos, puede resultar un método excesivamente caro y poco competitivo de obtener votos en comparación con el intercambio indirecto de la política programática. Ahora bien, ¿se extingue, por ello, el clientelismo? El intercambio de favores ha sabido adaptarse, reinventarse y dominar con su lógica nuevos campos, y aunque el clientelismo no explique el comportamiento electoral de las democracias postindustriales, reaparece con relativa frecuencia en el funcionamiento de los partidos de masas con miles de militantes, sedes locales y políticos en distintos niveles de instituciones, ajenos a las promociones meritocráticas.

\section{Referencias}

Auyero, Javier. 1999. «From the client's point of view: How poor people perceive and evaluate political clientelism", Theory and Society 28: 297-334. Disponible en: https://doi.org/10.1023/A:1006905214896.

Blakeley, Georgina. 2001. "Clientelism in the Building of State and Civil Society in Spain», en Simona Piattoni (ed.), Clientelism, Interests and Democratic Representation, Cambridge: Cambridge University Press.

Caciagli, Mario. 1996. Clientelismo, corrupción y criminalidad organizada. Madrid: Centro de Estudios Políticos y Constitucionales.

Castañeda, Diana. 2018. ¿Cuántos votos quieres? Trabajo político y movilización electoral en Cuajimalpa. Ciudad de México: Breviarios de Cultura Política Democrática.

Chubb, Judith. 1982. Patronage, power and poverty in southern Italy. Cambridge: Cambridge University Press.

Cinar, Kursat. 2016. «A comparative analysis of clientelism in Greece, Spain, and Turkey: the rural-urban divide», Contemporary Politics, 22, 77-94. Disponible en: https://doi.org/10.1080/13569775.2015.1112952.

Corzo, Susana. 2002. El clientelismo politico. El Plan de Empleo Rural en Andalucía: un estudio de caso. Granada: Editorial Universidad de Granada.

Coleman, James. 1990. Foundation of Social Theory. Cambridge: Harvard University Press.

Dahl, Robert. 1989. Democracy and Its Critics. Yale: Yale University Press. 
Della Porta, Donatella. 1992. Lo scambio occulto. Bolonia: Il Mulino.

Della Porta, Donatella y Yves Mény. 1995. Corruzione e democrazia. Nápoles: Liguori. Eisenstadt, Saul. y Lemarchand, René. 1981. Political clientelism, Patronage and Development. Londres: Sage. Disponible en: https://doi.org/10.1017/CBO9780511557743.

Eisenstadt, Saul y Louis Roniger. 1984. Patrons, Clients and Friends. Cambridge: Cambridge Universtiy Press.

Flap, Hendrik Derk. 1990. "Patronage: an institution in its own right», en M. Hechter, M. K. D. Opp y R. Wippler (eds.), Social Institutions. Nueva York: De Gruyter.

Gambetta, Diego. 1988. Trust. Making and Breaking cooperative relations. Oxford: Blackwell.

García, Mónica, Fernando Jiménez Manuel Villoria. 2014 «Can’t control/won’t control: opportunities and deterrents for local urban corruption in Lanzarote», Crime, Law and Social Change, 63: 1-20. Disponible en: https://doi.org/10.1007/ s10611-014-9549-z.

Geddes, Barbara. 1994. Political's Dilemma. Berkeley: California University Press.

George, Alexander y Andrew Bennett. 2005. Case studies and theory development in the social sciences. Cambridge, Massachusetts: MIT Press.

Gómez, Raúl y Tania Verge. 2011. «Party Patronage in Spain: A Appointments for Party Government», en Petr Kopecký, Peter Mair y Maria Spirova (eds.), Party Patronage and Party Government in European Democracies. Oxford: Comparative Politics. Disponible en: https://doi.org/10.1093/acprof:oso/9780199599370.003.0016.

Gordin, Jorge. 2009. «Regionalizing patronage? Federal resource allocation and party politics in Spain», Regional and Federal Studies, 19: 399-413. Disponible en: https://doi.org/10.1080/13597560902957492.

Graziano, Luigi. 1984. Clientelismo e sistema politico. Milán: F. Angeli.

Heidenheimer, Arnold, J., Michael Johnston y Victor T. Levine. 1989. Political Corruption. New Brunswick: Transaction.

Heywood, Paul. 1996. "Continuity and change: analysing political corruption in modern Spain», en E. Posada-Carbó y L. Walter (coords.), Political Corruption in Europe and Latin America. Nueva York: St. Martin's Press. Disponible en: https:// doi.org/10.1007/978-1-349-24588-8_6.

Hopkin, Jonathan. 2001. "A "Southern model" of electoral mobilisation?: Clientelism and electoral politics in Spain», West European Politics, 24: 115-136. Disponible en: https://doi.org/10.1080/01402380108425420.

Hopkin, Jonathan y Alfio Mastropaolo. 2001. «From Patronage to Clientelism: Comparing the Italian and Spanish Experiences», en Simona Piattoni (ed.), Clientelism, Interests and Democratic Representation. Cambridge: Cambridge University Press.

Huntington, Samuel 1968. Political order in changing societies. New Haven: Yale University Press.

Jiménez, Fernando. 2009. «Building boom and political corruption in Spain», South European Society and Politics, 14 (3): 255-272. Disponible en: https://doi. org/10.1080/13608740903356541. 
Johnston, Michael. 1986. "The political consequences of corruption», Comparative Politics, 18 (4): 459-477. Disponible en: https://doi.org/10.2307/421694.

Kitschelt, Herbert 2000. «Linkages between citizens and Political in democratic politics», Comparative Political Studies, 33 (6-7): 845-879. Disponible en: https://doi. org/10.1177/001041400003300607.

Kitschelt, Herbert y Steven Wilkinson. 2007. Patrons, Clients, and Policies: Patterns of Democratic Accountability and Political Competition. Cambridge: Cambridge University Press. Disponible en: https://doi.org/10.1017/CBO9780511585869.

Kopecký, Petr y Gerardo Scherlis. 2008. "Party patronage in contemporary Europe», European Review, 16 (3): 355-371. Disponible en: https://doi.org/10.1017/ S1062798708000306.

Löwy, Michael. 2004. "Le concept d'affinité élective chez Max Weber», Archives de Sciences sociales des Religions, 127: 93-103. Disponible en: https://doi.org/10.4000/ assr.1055.

Máiz, Ramón. 2003. «Jama, caleta y camello: la corrupción como mecanismo de autorrefuerzo del clientelismo político", Revista Mexicana de Sociología, 65 (1): 3-39. Disponible en: https://doi.org/10.2307/3541514.

Máiz, Ramón. 2005. «El clientelismo de partido y la corrupción política», en Montabes Pereira (coord.), Instituciones y procesos politicos. Madrid: Centro de Investigaciones Sociológicas.

Medina, Luis F. y Susan Stokes. 2007. «Monopoly and monitoring: A approach to political clientelism», en Herbert Kitschelt y Steven Wilkinson (coords.), Patrons, Clients, and Policies: Patterns of Democratic Accountability and Political Competition. Cambridge: Cambridge University Press.

Merton, Robert K. 1964. Teoría y estructuras sociales. México: Fondo de Cultura Económica.

Pantín, José 2017. Votos por favores: el clientelismo politico en la actualidad. Estudios de caso en la Galicia rural. Máiz, Ramón (dir.), Instituto Universitario de Investigación Ortega y Gasset, Universidad Complutense de Madrid. Disponible en: http://eprints.ucm.es/45524/.

Pantín, José 2019. Votos por favores. El clientelismo de partido en las instituciones gallegas. Madrid: Centro de Estudios Políticos y Constitucionales.

Roniger, Louis 1990. Hierarchy and Trust in Modern México and Brazil. Nueva York: Praeger.

Roniger, Louis. y Günes-Ayata, Ayse. 1994. Democracy, Clientelism and Civil Society. Boulder: Lynne Rienner.

Scott, James. 1972. "Patron client politics and political change in Southeast Asia», American Political Science Review, 66: 91-113. Disponible en: https://doi. org/10.2307/1959280.

Scott, James. 1974. «Natura e dinamica della politica clientelare nell'Asia Sud-orientale», en Luigi Graziano (coord.), Clientelismo e mutamento politico. Milán: F. Angeli. 
Stokes, Susan, T. Dunning, M. Nazareno y V. Brusco. 2013. Brokers, Voters, and Clientelism. Cambridge: Cambridge University Press.

Theobald, Robin. 1990. Corruption, Development and Underdevelopment. Londres:

MacMillan. Disponible en: https://doi.org/10.1007/978-1-349-20430-4.

Villoria, Manuel. 2006. La corrupción politica. Madrid: Síntesis.

Yin, Robert. K. 2003. Case study research. Design and Methods. Thousand Oaks: Sage.

Presentado para evaluación: 24 de noviembre de 2018.

Aceptado para publicación: 17 de julio de 2019.

\section{JOSÉ PANTÍN}

jose.pantin@usc.es

Investigador-colaborador de la Universidad de Santiago de Compostela, en el Equipo de Investigaciones Políticas del Departamento de Ciencia Política e Socioloxía. Doctor europeo en Gobierno y Administración Pública con Premio Extraordinario (UCM) por el Instituto Universitario de Investigación Ortega y Gasset (2017). Graduado en Ciencia Política y de la Administración por la Universidade de Santiago de Compostela (2011) y máster en Metodología de la Investigación en Ciencias Sociales en la Universidad Complutense de Madrid (2014). Sus temas de investigación de mayor interés son el clientelismo político, la corrupción, los mecanismos de vinculación políticos-ciudadanos y las estrategias para la distribución de políticas.

\section{RAMÓN MÁIZ}

ramon.maiz@usc.es

Catedrático de Ciencia Política en la Universidad de Santiago de Compostela. Ha publicado recientemente en revistas como Regional and federal Studies, Nationalism and Ethnic Politics, Journal of Political Ideologies, Studies in Ethnicity and Nationalism, Nations and Nationalism y Open Journal of Political Science. Algunos de sus últimos libros son: Ethnicisme et Politique, coeditado con Jean Tournon (2010); A Arte do Imposibel (2011); The Inner Frontier (2013); Teoría Politica, coeditado con E. García y A. Arteta (2014); Nacionalismo y federalismo (2018). Es miembro de la directiva del Comittee on Ethnicity and Politics de la IPSA, del Comité Académico del Centro de Filosofía de la Universidade de Lisboa (CFUL), y de los Consejos editoriales de Diversitas (Peter Lang), CIS y del Centro de Estudios Políticos y Constitucionales. También es miembro del comité internacional de redacción de las revistas: Nationalism and Ethnic Politics, Pôle Sud, Araucaria y Nations and Nationalism. 